\title{
The Conglomerate Discount: A New Explanation Based on Credit Risk
}

Manuel Ammann

Michael Verhofen

Working Paper Series in Finance

Paper No. 19 


\title{
The Conglomerate Discount: A New Explanation Based on Credit Risk
}

\author{
Manuel Ammann and Michael Verhofen* \\ University of St. Gallen
}

\begin{abstract}
We present a simple new explanation for the diversification discount in the valuation of firms. We demonstrate that, ceteris paribus, limited liability of equity holders is sufficient to explain a diversification discount. To derive this result, we use a credit risk model based on the value of the firm's assets. We show that a conglomerate can be regarded as an option on a portfolio of assets. By splitting up the conglomerate, the investor receives a portfolio of options on assets. The conglomerate discount arises because the value of a portfolio of options is always equal to or higher than the value of an option on a portfolio. The magnitude of the conglomerate discount depends on the number of business units and their correlation, as well as their volatility, among other factors.
\end{abstract}

\section{Introduction}

Recently, corporate diversification and its associated benefits and detriments have drawn considerable attention from academics and practitioners. In this paper, we propose a simple new explanation for the conglomerate discount. We model limited liability using an option-based credit risk model and show that a diversified company is valued - ceteris paribus - at a discount compared to a portfolio of focussed companies. The credit risk model used also allows for quantifying the magnitude of the conglomerate discount.

A number of hypotheses have been developed to explain the conglomerate discount. The academic arguments in favor or against diversification can be grouped into three different explanation approaches: agency theoretical, financial and strategic considerations.

\footnotetext{
*Manuel Ammann (manuel.ammann@unisg.ch) is professor of finance at the Swiss Institute of Banking and Finance, University of St. Gallen, Switzerland, and Michael Verhofen (verhofen@gmail.com) is visiting scholar at the Haas School of Business, University of California at Berkeley, United States of America. We thank an anoymous referee, Bernd Brommundt, Alexander Ising, Stephan Kessler, Axel Kind, Angelika Noll, Ralf Seiz, Stephan Süss, Rico von Wyss, and Andreas Zingg for valuable comments. We acknowledge financial support from the Swiss National Science Foundation (SNF).
} 
In agency theory, the disadvantages of corporate diversification are emphasized. The basic hypothesis is that managers act due to asymmetric information in their own interest and not in the best interest of the firm's shareholders. According to Jensen \& Murphy (1990), salary increases with firm size. Consequently, managers try to increase the size of the firm to increase their compensation. Jensen (1986) argues that managers are also interested in gaining power and prestige, which favors larger companies. According to Shleifer \& Vishny (1989), they also try to secure their position in the firm by making investments requiring their individual skills. Amihud \& Lev (1981) argue that the manager's private wealth highly depends on the firm's success and therefore managers reduce the firm's risk to a level consistent with their individual risk aversion. Asymmetric information within a company is examined by Myerson (1982). He argues that information asymmetry cost arising between the headquarter and the business units is higher in diversified companies.

Financial hypotheses provide contradicting arguments for the advantages of corporate diversification. In a diversified company, cashflows are less volatile, therefore, the default risk is lower and debt capacity increases. Lewellen (1971) argues that creditors are willing to accept higher leverage ratios and the value of the tax shield and therefore the value of the total company increases. Rating agencies give ceteris paribus a better rating to a company if the company is more diversified. Therefore, the cost of capital of a diversified company is lower. Majd \& Myers (1987) also focus on the effects of taxation. They argue that non-linear taxation favors diversification.

A couple of authors address capital budgeting decisions. There is also the danger of overinvestment Meyer, Milgrom \& Roberts (1992), inefficient allocation Rajan \& Servaes (2000) and cross-subsidization Stulz (1990). On the other hand, the underinvestment problem is reduced, as pointed out by Stulz (1990). Weston (1970) argues that internal capital markets are in general more efficient than external capital markets.

From a strategic perspective, a number of hypothesis have been formulated. Chandler (1977) argues that economies of scope in production and marketing and economies of scale in management can be exploited by entering other industries. Matsusaka (2001) argues that a company can leverage its capabilities by entering new markets. Villalonga (2000) argues that market power can be a motivation for diversification. The market power of a company can be improved or extended by entering different industries.

Although there are notable exceptions, it can be observed that older research tends to emphasize arguments in favor of diversification (e.g., Lewellen (1971), Weston (1970), Chandler (1977)), while more recent work tends to be more skeptical about the benefits of diversification (Whited (2001), Graham, Lemmon \& Wolf (2002)).

Empirically, there is substantial evidence that corporate diversification destroys shareholder value. Berger \& Ofek (1995) estimate a 13\% to $15 \%$ conglomerate discount for US companies in the period from 1986 to 1991. Tobin's q and firm diversification are nega- 
tively related during the 1980s and diversified firms underperform undiversified companies according to Lang \& Stulz (1994). Comment \& Jarrel (1995) find a positive relation between stock returns and focus. For the 1960s and early 1970s Servaes (1996) finds a diversification discount during the 1960s which declines to zero in the 1970s. Lins \& Servaes (1999) estimate for the years 1992-1994 no diversification discount in Germany, but a $10 \%$ discount in Japan and a 15\% discount in the U.K. According to Morck, Shleifer \& Vishny (1990), financial markets react negatively to diversifying takeovers. In contrast, spin-offs generate value for the parent company, as observed by Daley, Mehrotra \& Sivakumar (1997). According to Hyland \& Diltz (2002), however, it is still doubtful whether there is a causality between diversification and value destruction or whether both observations depend on a third common factor.

Empirical investigations concerning the diversification discount face a number of estimation problems, which make it hard to compare diversified and focussed companies. A simple way of measuring the magnitude of diversification is to count the number of industry groups in which a company is active. Using classifications such as the Standard Industrial Classification (SIC) codes may lead to misleading results because in one industry group many different business models can be summarized. According to Martin \& Sayrak (2003) the entropy measure, which tries to overcome shortcomings of a simple business count measure, takes three elements into account to estimate the magnitude of diversification: the number of industries in which a firm operates, the distribution of the firm's total sales/assets across the industry segments, and the degree of relatedness among the various industries. Other estimate issues include the usage of accounting number instead of market values and database limitations.

In this paper, we contribute a new explanation to the discussion of the conglomerate discount that is based on the structural model of the firm as proposed by Merton (1974). The model is an option-based approach because the limited liability of the equity is regarded as a call option of the equity holders. Thus, our explanation of the diversification discount uses a credit risk model reflecting the limited liability of equity holders. We show that, by limited liability alone, the value of a diversified firm is reduced compared to the value of the sum of its business units.

In the following section, we present the credit risk model and show that it implies a diversification discount. This discount is quantified in Section 3. In Section 4, we discuss empirical implications and the robustness of our conclusion with respect to the credit risk model. We conclude in Section 4.

\section{Model with Limited Liability}

Consider a firm whose asset value $V$ follows a stochastic process according to: 


$$
\frac{d V}{V}=\mu d t+\sigma d W
$$

where $\mu$ is the instantaneous expected rate of return, $\sigma$ the variance of the return of the value of the assets, and $W$ is a Brownian motion. We assume $\mu$ and $\sigma$ to be constant over time. A riskless asset is available and its rate of return $r$ is known and constant over time.

The total value of the firm $V$ is financed by equity $E$ and one representative zerocoupon noncallable bond $D$ with maturity at time $T$, a face value $F$ and a yield to maturity of $y$. The debt contract is fixed and at $t$ the firm is not yet in default. We refer to the ratio $\frac{F}{V}$ as the leverage $l$ of the company. For simplicity, we assume that markets are frictionless (no transaction costs, no taxes, assets are perfectly divisible and traded continuously, no short-selling restrictions, no bid-ask-spreads, no asymmetry, equal borrowing and lending rates) and atomistic (many investors with a comparable level of wealth, investors cannot influence the market price). Therefore, the value of the firm does not depend on the capital structure itself. In this respect, our model is consistent with the Modigliani-Miller setup.

At maturity $T$, the value of the firm $V$ is compared to the value of the debt $D$, which, at that time, equals its face value $F$. If, at maturity, the value of the firm $V$ is below the value of the debt $D$, equity $E$ has a negative value. Assuming limited liability for equity $E$, the company declares bankruptcy and the assets of the company are handed over to the debt holders. Since $V-F<0$, debt holders suffer a loss. The payoff of the debt at maturity is therefore $\min \left(V_{T}, F\right)$. The payoff of the equity is $\max \left(V_{T}-F, 0\right)$.

We assume that there are no cashflows during the lifetime of the bond, that no new securities are issued and that there are no bankruptcy costs. Default can only happen at maturity $T$ and shareholders only obtain a positive payoff if debt holders are fully reimbursed.

If $V$ is equal to or larger than $F$, equity holders receive the difference $V-F$ and debt holders are fully reimbursed. The payoffs at time $T$ are as follows:

\begin{tabular}{ccc}
\hline & Debt & Equity \\
\hline$V_{T}<F$ & $V_{T}$ & 0 \\
$V_{T} \geq F$ & $F$ & $V_{T}-F$ \\
\hline
\end{tabular}

The limited liability of the equity can be regarded as a long call option of the equity holder on the assets of the firm with strike price $D$. Alternatively, it can be viewed as a short put option held by the debt holders.

If the Black-Scholes assumptions hold (e.g. $\sigma$ is constant, risk-neutral valuation is possible because the underlying security is tradable), the value of the equity $C_{t}$ is given by the price of a Black-Scholes option on the firm value $V$, i.e, 


$$
C_{t}(V, T, \sigma, r, F)=V_{t} N\left(d_{1}\right)-F e^{-r(T-t)} N\left(d_{2}\right)
$$

with

$$
d_{1}=\frac{\ln \left(\frac{V_{t}}{F}\right)+\left(r+\frac{\sigma^{2}}{2}\right)(T-t)}{\sigma \sqrt{T-t}}, d_{2}=d_{1}-\sigma \sqrt{T-t}
$$

To explain the conglomerate discount we extend this model in a number of ways. First, the firm and their assets can be split into $n$ separate entities. Before separation, we refer to these entities as the "business units" and to the whole firm as the "diversified firm". After separation, we refer to these entities as the "focussed firms" and to the whole firm as the "portfolio of focussed firms".

Second, each business unit $i$ can be characterized by the asset value $V_{i}$, the debt $D_{i}$ and its face value $F_{i}$, the equity $E_{i}$, the leverage $l_{i}=\frac{F_{i}}{V_{i}}$, and the asset volatility $\sigma_{i}$. The weight of a business unit $w_{i}$ is defined as $\frac{V_{i}}{V}$. The asset values and the face values must add up, i.e., $\sum_{i=1}^{n} V_{i}=V, \sum_{i=1}^{n} F_{i}=F$. We further assume that no business unit is in default at time $t$.

Third, we assume that the value of the assets of a business unit follows the stochastic process in equation 1 . The correlation of returns on asset values between separate business unit $i$ and $j$ can be described by the correlation coefficient $\rho_{i j}$.

For the diversified firm, the payoffs at maturity are

\begin{tabular}{ccc}
\hline & Debt & Equity \\
\hline$\sum V_{i T}<\sum F_{i}$ & $\sum V_{i T}$ & 0 \\
$\sum V_{i T} \geq \sum F_{i}$ & $\sum F_{i}$ & $\sum V_{i T}-\sum F_{i}$ \\
\hline
\end{tabular}

The payoff of the equity $P$ can therefore be written as

$$
P_{O o P, T}=\max \left(\sum_{i=1}^{n} V_{i T}-\sum_{i=1}^{n} F_{i}, 0\right) .
$$

In option pricing terms, this is an option on a portfolio (OoP).

The value of the assets of the diversified firm does not follow a standard stochastic process because the sum of geometric Brownian motions is not a geometric Brownian motion. Therefore, standard option pricing formulas are not applicable.

To price a claim $C_{O o P}$ with the payoff $P_{O o P, T}$, we simulate 100.000 price paths for each business unit and compute the asset value of the diversified firm as the sum of the asset values of the single business units. The price of the claim $C_{O o P, t}$ is given by

$$
C_{O o P, t}=e^{-r(T-t)} E_{Q}\left(P_{O o P, T}\right)
$$

where $E_{Q}$ is the risk-neutral expectation. 


\begin{tabular}{ccc|ccc}
\hline \multicolumn{3}{c|}{ Cases } & \multicolumn{3}{c}{ Payoffs } \\
$V_{1}$ & $V_{2}$ & $V$ & Portfolio of Options & Option on Portfolio \\
\hline$V_{1}<F_{1}$ & $V_{2}<F_{2}$ & & 0 & $=$ & 0 \\
& $V_{2} \geq F_{2}$ & $V<F$ & $V_{2}-F_{2}$ & $>$ & 0 \\
& & $V \geq F$ & $V_{2}-F_{2}$ & $>$ & $V_{2}-F_{2}+V_{1}-F_{1}$ \\
$V_{1} \geq F_{1}$ & $V_{2}<F_{2}$ & $V<F$ & $V_{1}-F_{1}$ & $>$ & 0 \\
& & $V \geq F$ & $V_{1}-F_{1}$ & $>$ & $V_{1}-F_{1}+V_{2}-F_{2}$ \\
$V_{1} \geq F_{1}$ & $V_{2} \geq F_{2}$ & & $V_{1}-F_{1}+V_{2}-F_{2}$ & $=$ & $V_{1}+V_{2}-F_{1}+F_{2}$ \\
\hline
\end{tabular}

Table 1: Comparision of Payoffs

In the portfolio of focussed firms the situation at maturity is different. For each firm, asset value and debt are compared and the payoff is

\begin{tabular}{ccc}
\hline & Debt & Equity \\
\hline$V_{i T}<F_{i}$ & $V_{i T}$ & 0 \\
$V_{i T} \geq F_{i}$ & $F_{i}$ & $V_{i T}-F_{i}$ \\
\hline
\end{tabular}

The payoff of the equity of one focussed company $P_{i, T}$ can therefore be written as $P_{i, T}=\max \left(V_{i T}-F_{i}, 0\right)$ for all $i \in\{1, \ldots, n\}$. Consequently, the payoff of the portfolio of focussed firms $P_{P o O}$ is the sum of the individual payoffs $P_{i, T}$, i.e.,

$$
P_{P o O, T}=\sum_{i=1}^{n} P_{i, T}=\sum_{i=1}^{n} \max \left(V_{i, T}-F_{i}, 0\right) .
$$

Hence, the investor holds a portfolio of options. The value of the equity of an individual company is $C_{i, t}\left(V_{i}, T, \sigma_{i}, r, F_{i}\right)=V_{i, t} N\left(d_{1}\right)-F_{i} e^{-r(T-t)} N\left(d_{2}\right)$. Assuming that there are no explicit or implicit guarantees for the liabilities between the firms, the value of the entire portfolio of focussed companies is the sum of the value of the single firms, namely $C_{P o O, t}=\sum_{i=1}^{n} C_{i, t}$.

Table 1 compares the payoffs at time $T$ for $n=2$. The payoff of the portfolio of options is never smaller than the payoff of the option on a portfolio, but sometimes greater. The value of the portfolio of options must therefore be higher than the value of the option on a portfolio. Hence, the value of a conglomerate firm consisting of a number of business units is lower than the sum of the values of the business units run as individual focussed firms.

The model presented above is based on the credit risk model by Merton (1974). However, it is not restricted to this particular credit risk model. Our conclusion regarding the diversification discount is valid for any credit risk model as long as limited liability prevails, i.e., the option-like nature of equity is preserved. This is the case for a number of different credit risk models, such as extensions of the original model by Merton (1974). 


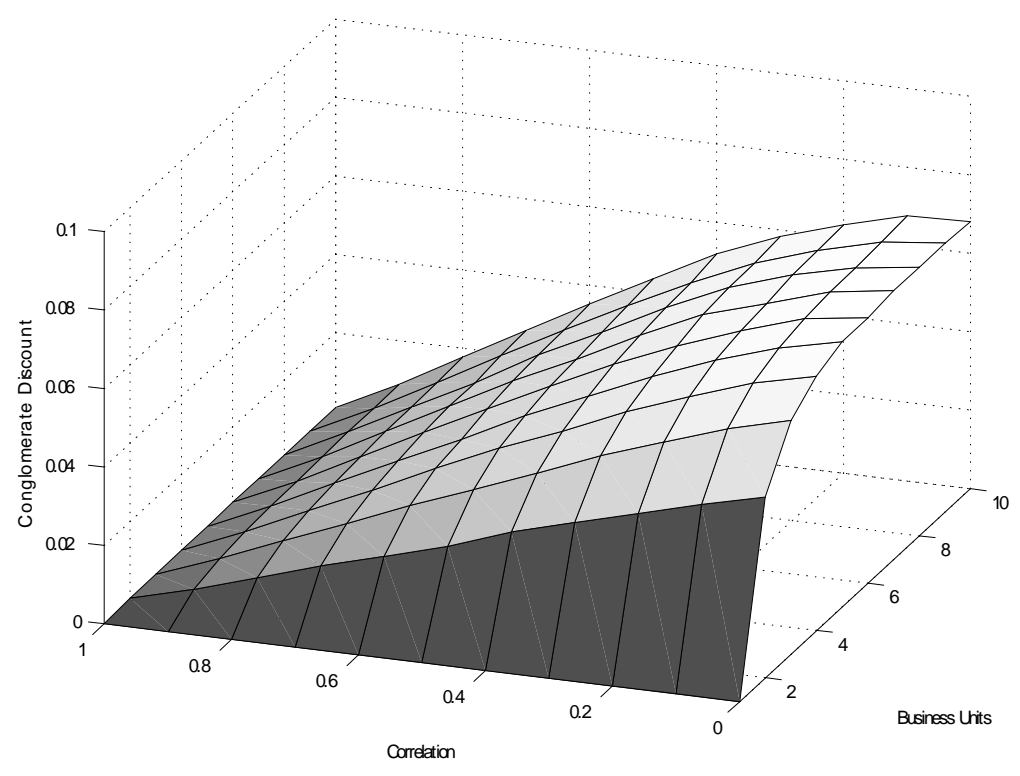

Figure 1: Impact of Number of Business Units and Correlation on Diversification Discount. Parameters: $V=100, F=80, l=0.8, T=5, r=5 \%, \sigma_{i}=20 \%, w_{i}=\frac{1}{n}, V_{i}=w_{i} V$, $F_{i}=w_{i} F \forall i \in\{1, \ldots, n\}$

Such extensions include adaptations to different types of securities with different maturity dates, different classes of seniority, different recovery rates, and interest rates following specific stochastic processes. An example for such a extension is Leland (1994) and Leland \& Toft (1996). They allow for coupon payments, a tax shield due to the tax benefits of interest payments and bankruptcy costs.

\section{Magnitude of the Conglomerate Discount}

In this section we apply the model to estimate the size of the conglomerate discount and the sensitivity to changes in parameters. We define the conglomerate discount $L$ as

$$
L_{t}=\frac{C_{P o O, t}-C_{O o P, t}}{C_{P o O, t}} .
$$

In a first step we analyze the effect of splitting up a company into a number of different business units of different correlation. We vary the number of business units from 1 to 10 and the correlation from 0 to 1 in steps of 0.1 . Figure 1 illustrates the effect of an increasing number of business units and increasing correlation.

Our analysis shows that the correlation has a negative impact on the conglomerate discount: the higher the correlation, the lower the conglomerate discount. In the extreme case of perfect correlation the conglomerate discount disappears completely. 


\begin{tabular}{c|cccccccccc}
\hline$\rho$ & \multicolumn{10}{|c}{ Number of Business Units } \\
& 1 & 2 & 3 & 4 & 5 & 6 & 7 & 8 & 9 & 10 \\
\hline 0.0 & 0.00 & 4.64 & 6.04 & 6.48 & 6.70 & 6.81 & 6.82 & 6.78 & 6.91 & 6.86 \\
0.1 & 0.00 & 4.26 & 5.51 & 6.10 & 6.42 & 6.48 & 6.57 & 6.73 & 6.65 & 6.73 \\
0.2 & 0.00 & 3.77 & 5.05 & 5.59 & 5.88 & 6.05 & 6.20 & 6.28 & 6.32 & 6.44 \\
0.3 & 0.00 & 3.37 & 4.45 & 4.95 & 5.29 & 5.50 & 5.57 & 5.67 & 5.77 & 5.88 \\
0.4 & 0.00 & 2.90 & 3.87 & 4.31 & 4.58 & 4.80 & 4.93 & 5.04 & 5.11 & 5.16 \\
0.5 & 0.00 & 2.41 & 3.23 & 3.66 & 3.88 & 4.00 & 4.14 & 4.27 & 4.26 & 4.38 \\
0.6 & 0.00 & 1.95 & 2.56 & 2.92 & 3.10 & 3.29 & 3.33 & 3.38 & 3.49 & 3.53 \\
0.7 & 0.00 & 1.45 & 1.98 & 2.14 & 2.35 & 2.43 & 2.50 & 2.59 & 2.60 & 2.64 \\
0.8 & 0.00 & 0.98 & 1.32 & 1.45 & 1.58 & 1.64 & 1.67 & 1.71 & 1.74 & 1.79 \\
0.9 & 0.00 & 0.49 & 0.64 & 0.72 & 0.78 & 0.82 & 0.82 & 0.85 & 0.88 & 0.89 \\
1.0 & 0.00 & 0.00 & 0.00 & 0.00 & 0.00 & 0.00 & 0.00 & 0.00 & 0.00 & 0.00 \\
\hline
\end{tabular}

Table 2: Impact of number of business units and correlation on the conglomerate discount (in percent). Parameters as in Figure 1. Monte Carlo simulation with 100.000 iterations.

These findings offer a straightforward economic interpretation: if business units are "similar" to each other, e.g. their are focussing on similar markets or products, the conglomerate destroys less value than in the case of a conglomerate of unrelated activities.

The number of business units is positively related to the conglomerate discount: the more business units, the higher the conglomerate discount. As Table 2 shows, the conglomerate discount depends of the combination of the correlation and the number of different business units. The data suggest that the impact of additional business units on the conglomerate discount is relatively small if there are at least 3 business units.

Overall, the model shows that in the base case the conglomerate discount does not exceed $7 \%$.

In a second step we analyze the effect of the volatility of the assets and on the capital structure on the conglomerate discount. We vary the volatility of the assets from $5 \%$ to $100 \%$ and the proportion of debt from $0 \%$ to $100 \%$. Figure 2 shows the result.

In our model the leverage has a strict positive impact on the conglomerate discount if all other parameters stay constant. The interpretation is straightforward: The higher the proportion of the debt, the higher the default risk and the probability that equity holders only participate in a favorable upward movement. If there are separate focussed firms, equity holders can participate in the upward movements of successful companies. Only unsuccessful companies are handed over to the debt holders.

Volatility has a mixed effect on the conglomerate discount. Very low volatility leads to a very low conglomerate discount. In the case of certainty the conglomerate discount 


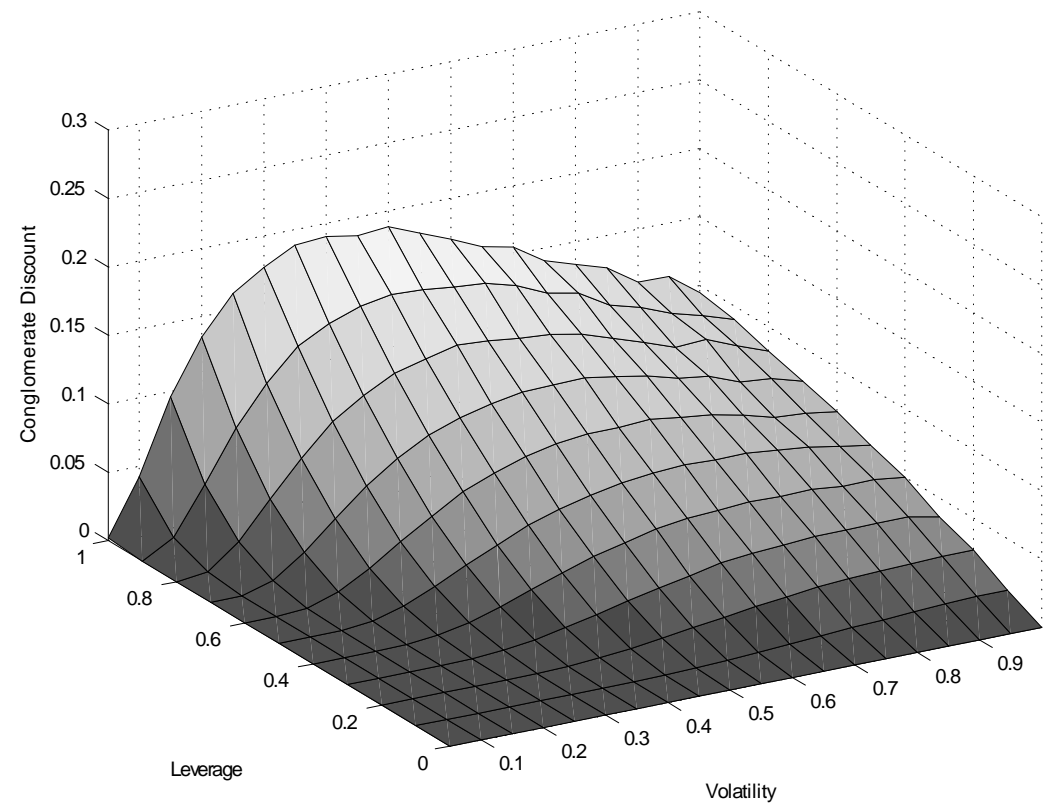

Figure 2: Impact of Volatility and Leverage on Diversification Discount. Parameters: $V=100, T=5, r=5 \%, n=2, \rho=0, w_{i}=\frac{1}{n}, \rho=0, V_{i}=w_{i} V, F_{i}=w_{i} F \forall i \in\{1, \ldots, n\}$

disappears because no credit risk is present. Increasing the volatility increases the conglomerate discount. The slope of the increase depends heavily on the capital structure. After reaching a maximum the conglomerate discount decreases as we increase volatility further.

As the next step we analyze the effect of changes in the interest rate and changes in the maturity of the debt. We vary the interest rate from $0 \%$ to $20 \%$ and the time to maturity from 1 period to 10 periods.

Figure 3 illustrates the findings. The interest rate has a negative impact on the conglomerate discount: the higher the interest rate, the lower the conglomerate discount. This finding might be important for comparing conglomerate discounts in different countries. The model suggests that the conglomerate discount is higher in countries that have a low interest rate. In general, the time to maturity of outstanding debt has a positive impact on the conglomerate discount because longer maturities usually imply high credit risk. The magnitude of the impact depends on the combination of interest rate and time to maturity. 


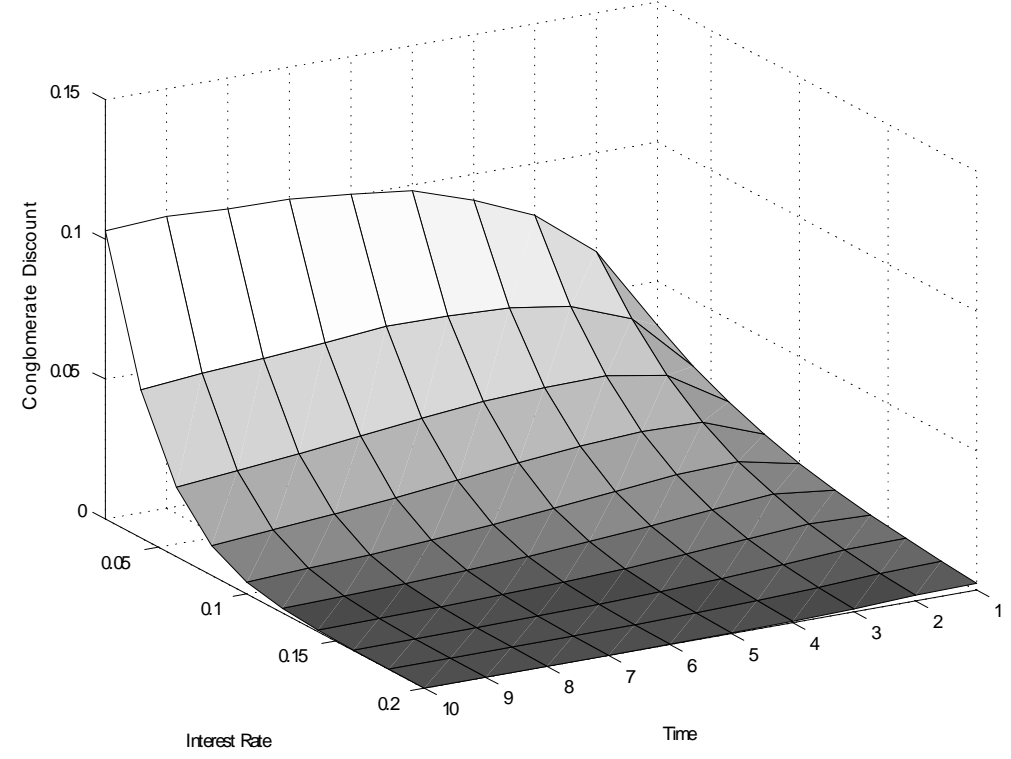

Figure 3: Impact of Interest Rate and Time on Diversification Discount. Parameters: $V=100, F=80, l=0.8, n=2, \sigma_{i}=20 \%, w_{i}=\frac{1}{n}, \rho=0, V_{i}=w_{i} V, F_{i}=w_{i} F \forall$ $i \in\{1, \ldots, n\}$

\section{Discussion}

Although the fundamental insight of limited liability as an explanation for the diversification discount persists for any credit risk model that allows equity to be interpreted as an option on the value of the firms assets, the magnitude of the diversification discount for a given set of parameters depends on the option pricing model and the credit risk model used. In our case, the model is an extension of the firm value model by Merton (1974).

To quantify the impact of the credit risk model on the magnitude of the resulting diversification discount, we also conduct a numerical analysis based on an alternative credit risk model. The model by Merton (1974) assumes that default can only occur at maturity. We therefore use as an alternative credit risk model the model by Black \& Cox (1976). In this model, default can happen at any time before maturity when the firm value hits the default barrier. In this case, the value of the equity is given by a down-and-out call option price.

In the Monte Carlo framework, the implementation of the Black-Cox model is straightforward. We simulate 100, 000 price paths at 50 steps each. At each step, default for each single business unit and for the whole conglomerate can occur. We assume that default occurs if the firm value drops below the present value of the zero bond.

Figure 4 illustrates the numerical results. The upper surface represents the base case where default can only occur at maturity. The lower surface represents the extended case 


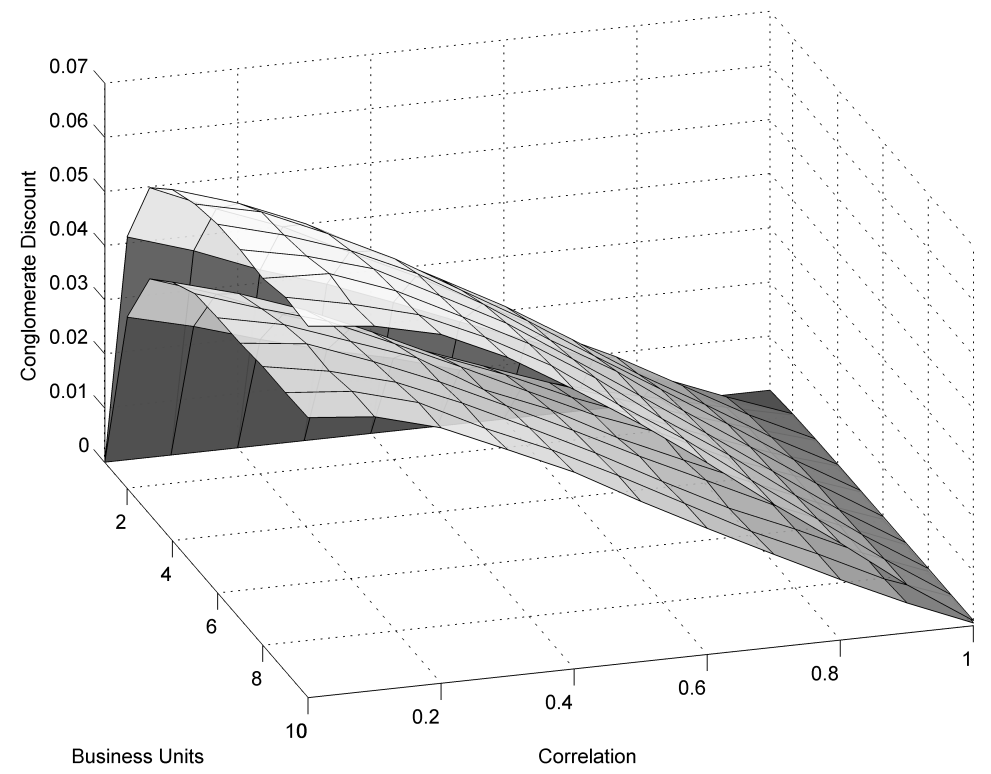

Figure 4: Impact of Number of Business Units and Correlation on Diversification Discount where default can occur at any time (lower surface) and where default can only occur at maturity (upper surface). Parameters : $V=100, F=80, l=0.8, T=5, r=5 \%$, $\sigma_{i}=20 \%, w_{i}=\frac{1}{n}, V_{i}=w_{i} V, F_{i}=w_{i} F \forall i \in\{1, \ldots, n\}$

where default can occur before maturity. We find that, whereas the conglomerate discount is always smaller for the alternative model than for the base case, there is still a substantial discount. On average, the conglomerate discount for the extended case is approximately $66 \%$ of the discount in the base case. However, this ratio changes for depending on the parameters. In general, the higher the correlation is, the higher is the reduction of the conglomerate discount. For example, for a correlation of 0.9 , the conglomerate discount for the alternative model is $61 \%$ of the discount in the base case. For a correlation of 0 , this ratio increases to $74 \%$.

Although the scope of this paper is only theoretical, the model proposed in the previous section can be tested empirically. An empirical test could draw from two branches of literature, namely the empirical credit risk literature and the empirical conglomerate discount literature. For example, Ho Eom, Helwege \& Huang (2004) analyze the empirical performance of various structural credit risk models (Merton (1974), Geske (1977), Longstaff \& Schwartz (1995), Leland \& Toft (1996), Collin-Dufresne \& Goldstein (2001)). Using bond prices for companies with simple capital structures, they find that the spreads predicted by the Merton model are too low, whereas the spreads predicted by other models are too high. Following Ho Eom et al. (2004), a credit risk model is superior if observed credit 
spreads are predicted in a better way. This test design can be, in general, transferred to test the conglomerate discount model presented in this paper.

However, a number of problems might arise additionally to the issues encountered by Ho Eom et al. (2004). In contrast to the models analyzed by Ho Eom et al. (2004), a closed-form solution does not exist for our model. Therefore, numerical procedures must be used to compute credit spreads and other parameters of interest. Moreover, in our model some parameters might be unobservable, such as the covariance-matrix for the firm values of the single business units. Since single business units are usually non-traded assets, price data cannot be used to estimate the covariance-matrix. As a proxy, the covariance-matrix based on revenue, earnings, or cash flow growth might be used. Instead of pursuing a direct test of the credit risk model, an indirect, implication-based test can be used. Therefore, the second possible test design is similar to a standard analysis of conglomerate discount models.

Empirical analyses of conglomerate discount models face a number of difficulties, as pointed out in Campa \& Kedia (2002). First, the conglomerate discount is not a directly observable variable. Therefore, proxy variables (such as stock market valuation ratios) have to be used. Second, corporate diversification is an active decision taken by the management. As firms choose to diversify if the perceived benefits of diversification overweight the costs of corporate diversification, a hidden self-selection mechanism drives corporate diversification. From an econometric point of view, the conglomerate discount is an endogenous variable and this can be taken into account as in Campa \& Kedia (2002).

In the frameworks used by a number of authors, such as Berger \& Ofek (1995) and Servaes (1996), an empirical test of the model proposed in this paper can be pursued as follows. The models claims that there is a relation between the magnitude of the conglomerate discount and the number of business units, their correlations, the leverage, the volatility, the interest rate, and the time to maturity. The impact of these factors can be analyzed by using regressions and has been analyzed, at least partially, in a number of studies, for example Berger \& Ofek (1995), Servaes (1996), and Campa \& Kedia (2002).

Servaes (1996) studies the impact of the number of business units (segments) on the conglomerate discount. He finds for some periods of time a significant reduction in a firm's value if a firm operates in more than one segment. However, he finds no further decrease in value beyond the second segment. This is, at least to some degree, consistent with our model because the conglomerate discount in the model does not increases materially after the second business unit. Berger \& Ofek (1995) find that the value loss is smaller when the segments of the diversified firm are in the same two-digit SIC code. This finding is consistent with our model's predictions if the correlation between business units is proxied by the SIC code and comparable SIC codes are interpreted as high correlations. Campa \& Kedia (2002) analyze, beside a number of other factors, the impact of leverage on 
the conglomerate discount. They find a positive relation between the degree of leverage and the conglomerate discount, which is consistent with our model. The impact of the remaining factors (volatility, interest rate, and time to maturity) has not yet been studied empirically, to our knowledge.

\section{Conclusion}

In this paper, we propose a simple new explanation for the conglomerate discount. Our explanation is derived from a credit risk framework modeling limited liability of shareholders as an option of the assets of the firm. In this framework, we show that a conglomerate firm consisting of a number of individual business units can be viewed as an option on a portfolio of assets. In contrast, if the business units were run as separate firms, investors would hold a portfolio of options on the assets of the respective business unit. Because the value of an option on a portfolio of assets is smaller than the value of a portfolio of options on the individual assets, the diversification discount is a simple consequence of limited liability.

We show in our model that the magnitude of the conglomerate discount depends on six factors: (1) number of business units, (2) the correlation between the business units, (3) the volatility of the asset value, (4) the financial leverage, (5) the interest rate, and (6) the time to maturity. Correlation is the only factor having always a negative impact on the conglomerate discount. The number of business units, the financial leverage, the interest rate and the time to maturity always increase the conglomerate discount. The impact of a change of the volatility of the asset value is ambiguous. For low volatilities, an increase in volatility leads to an increase in the conglomerate discount.

According to our model, corporate diversification reduces shareholder value, ceteris paribus. Hence, for corporate diversification to be beneficial to shareholders, potential advantages of diversification need to overcompensate the fundamental disadvantage of diversification caused by limited liability.

\section{References}

Amihud, Y. \& Lev, B. (1981), 'Risk reduction as a managerial motive for conglomerate mergers', Bell Journal of Economics 12, 605-618.

Berger, P. \& Ofek, E. (1995), 'Diversifiation's effect on firm value', Journal of Financial Economics 37, 39-65.

Black, F. \& Cox, J. C. (1976), 'Valuing corporate securities: Some effects of bond indenture provisions', Journal of Finance 31, 351-367. 
Campa, J. M. \& Kedia, S. (2002), 'Explaining the diversification discount', Journal of Finance 57, 1731-1762.

Chandler, A. (1977), The Visible Hand, Belknap Press, Cambridge, MA.

Collin-Dufresne, P. \& Goldstein, R. (2001), 'Do credit spreads reflect stationary leverage ratios?', Journal of Finance 56, 1929-1957.

Comment, R. \& Jarrel, G. (1995), 'Corporate focus and stock returns', Journal of Financial Economics 37, 67-87.

Daley, L., Mehrotra, V. \& Sivakumar, R. (1997), 'Corporate focus and value creation: Evidence from spinoffs', Journal of Financial Economics 45, 257-281.

Geske, R. (1977), 'The valuation of corporate liabilities as compound options', Journal of Financial and Quantitative Analysis 12, 541-552.

Graham, J. R., Lemmon, M. L. \& Wolf, J. G. (2002), 'Does corporate diversification destroy value?', Journal of Finance 57, 695-720.

Ho Eom, Y., Helwege, J. \& Huang, J.-Z. (2004), 'Structural models of corporate bond pricing: An empirical analysis', Review of Financial Studies 17, 499-544.

Hyland, D. C. \& Diltz, J. D. (2002), 'Why firms diversify: An empirical examination', Financial Management 31, 51-81.

Jensen, M. (1986), 'Agency costs of free cash flow', American Economic Review 76, 323329.

Jensen, M. \& Murphy, K. J. (1990), 'Performance pay and top-management incentives', Journal of Political Economy 98, 225-264.

Lang, L. \& Stulz, R. (1994), 'Tobin's q, corporate diversification and firm performance', Journal of Political Economy 102, 1248-1281.

Leland, H. (1994), 'Corporate debt value, bond convenants, and optimal capital structure', Journal of Finance 49, 1213-1252.

Leland, H. \& Toft, K. (1996), 'Optimal capital structure, endogenous bankruptcy, and the term spread of credit spreads', Journal of Finance 51, 987-1019.

Lewellen, W. (1971), 'A pure financial rationale for the conglomerate merger', Journal of Finance 26, 521-537.

Lins, K. \& Servaes, H. (1999), 'International evidence on the value of corporate diversification', Journal of Finance 54, 2215-2239. 
Longstaff, F. \& Schwartz, E. (1995), 'Valuing risky debt: A new approach', Journal of Finance 50, 789-820.

Majd, S. \& Myers, S. (1987), Tax asymmetries and corporate income tax reform, in M. Feldstein, ed., 'Effects of Taxation on Capital Accumulation', University of Chicago Press, Chicago, IL.

Martin, J. D. \& Sayrak, A. (2003), 'Corporate diversification and shareholder value: A survey of recent literature', Journal of Corporate Finance 9, 37-57.

Matsusaka, J. G. (2001), 'Corporate diversification, value maximization, and organizational capabilities', Journal of Business 74, 409-431.

Merton, R. (1974), 'On the pricing of corporate debt', Journal of Finance 29, 449-471.

Meyer, M., Milgrom, P. \& Roberts, J. (1992), 'Organizational prospects, influence costs, and ownership changes', Journal of Economics and Management Strategy 1, 9-35.

Morck, R., Shleifer, A. \& Vishny, R. (1990), 'Do mangerial objectives drive bad acquisitions?', Journal of Finance 45, 31-48.

Myerson, R. (1982), 'Optimal coordination mechanisms in generalized principal-agent problems', Journal of Mathematical Economics 10, 67-81.

Rajan, R. \& Servaes, H. (2000), 'The cost of diversity: The diversification discount and inefficient investment', Journal of Finance 55, 35-79.

Servaes, H. (1996), 'The value of diversification during the conglomerate merger wave', Journal of Finance 51, 1201-1225.

Shleifer, A. \& Vishny, R. W. (1989), 'Mangement entrenchment', Journal of Financial Economics 25, 123-140.

Stulz, R. (1990), 'Managerial discretion and optimal financing policies', Journal of Financial Economics 26, 3-27.

Villalonga, B. (2000), 'Privatization and efficiency: Differentiating ownership effects from political, organizational, and dynamic effects', Journal of Economic Behaviour and Organization 42, 43-74.

Weston, J. (1970), 'The nature and significance of conglomerate firms', St. John's Law Review 44, 66-80.

Whited, T. M. (2001), 'Is it inefficient investment that causes the diversification discount?', Journal of Finance 56, 1667-1691. 